\title{
Design of a PV Based Power Supply with a Non- Inverting Buck-Boost Converter
}

\author{
Kingsley A. Ogudo \\ Department of Electrical and Electronics Engineering \\ Technology \\ Faculty of Engineering and the Built Environment \\ University of Johannesburg \\ kingsleyo@uj.ac.za
}

\author{
Patrice Umenne \\ Department of Electrical and Mining Engineering \\ University of South African (UNISA) \\ Johannesburg, South Africa \\ umennpo@unisa.ac.za
}

\begin{abstract}
This paper presents the design of a photovoltaic based power supply using a non-inverting buck-boost converter to charge batteries. The batteries can be used to power a load as back-up power when there is no sunlight. This approach presents a constant output of $48 \mathrm{~V}$ charging voltage for the batteries even though the input voltage may vary depending on the amount of solar irradiation falling on the solar panel. Solar charge controllers are important components in such an off-grid system because they can be used to protect the battery bank from overcharging and regulate the charging current. The buck-boost converter is used as a solar charge controller to maximize the charging voltage when the solar irradiation provides less than the required output voltage. The DC-DC converter (buck-boost converter) was modelled using the SIMetrix software to demonstrate the expected output waveforms before building the complete $P V$ power supply.
\end{abstract}

Index Terms - Buck-boost converter, DC-DC converter, Photovoltaic (PV) System, Solar charge controller, SIMetrix software.

\section{INTRODUCTION}

Renewable energy such as solar, wind, hydro, biogas and nuclear are many of the promising solutions that can be used to address the lack of access to clean electricity. Renewable energy can help to reduce the greenhouse gas emissions produced by fossil fuels such as coal and diesels. Many rural parts of the continent still lack access to electricity and clean drinking water. As a result, most of these communities, still rely on fossil fuels to perform daily activities such as lighting, cooking and heating. In subSaharan Africa and Asia $84 \%$ of people lack access to electricity, where majority of these are rural dwellers [1]. Therefore, solar energy is one of the proposed methods of providing cleaner, safer and reliable energy to rural communities, especially where communities are not connected to the power grid. Solar energy is free, abundant and cheaper for powering homes with enough energy. This can be achieved by proper planning and execution, through which all the energy requirements may be met costeffectively [2].

\section{METHODOLOGY}

\section{A. PV Systems}

Solar panels convert solar energy into electrical energy. Most of the electrical energy is in the form of direct current. The direct current (d.c.) is connected to the solar charge controller for charging the batteries. Photovoltaic systems are classified according to their functionality and method of operation and careful consideration is given to customer requirements. Types of PV systems [3], [4] include grid connected, hybrid system and off-grid systems.

Grid connected solar systems are systems which are connected in parallel with the national grid. This solar system utilises an inverter to invert the DC voltage from the solar panels into AC.

The hybrid system is a combination of renewable energies (Solar, wind turbines, biogas) which are connected with the aim of providing stable power. In this system subcomponents complement one another in such a way that when one component does not supply sufficient power then another component takes over. Back-up storage is also used in this system in the case where renewable sources are not operating in favourable weather condition. Fig. 1 shows an example of a hybrid PV system.

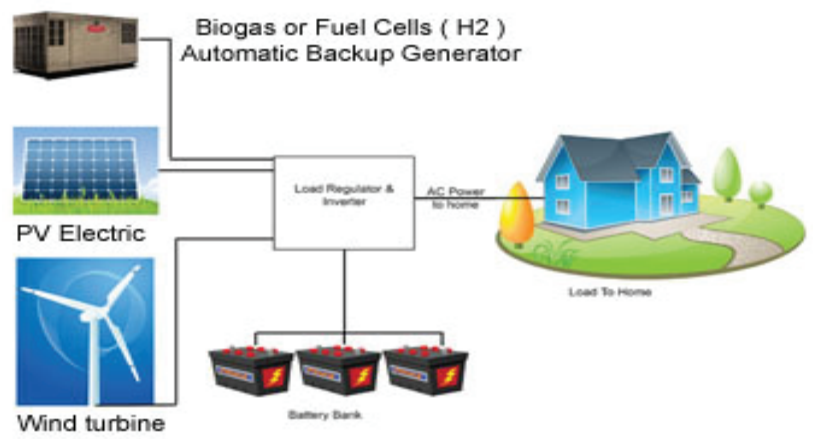

Fig. 1 Example of hybrid system [5]

The off-grid or stand-alone system as the name refers is not connected to the national grid. It supplies its own power during the day and at night and uses batteries as a back up. 


\section{IEEE PES/IAS PowerAfrica}

This system requires a solar charge controller for efficient charging of batteries and battery regulation.

\section{B. Charge controllers}

Batteries are an important back-up system when using a stand-alone or off-grid PV system because it provides reliable power during the night when there is no solar radiation. Charge controllers are responsible for regulating the battery charge and preventing the battery from overcharging from the solar panels and discharging excessively due to the load. Therefore, charge controllers are vital for battery optimum performance. Charge controllers are also responsible for extracting the right amount of power from the solar panels to charge the battery by varying the time taken to charge the battery bank. Fig.2 is a block diagram showing the connection of the charge controller.

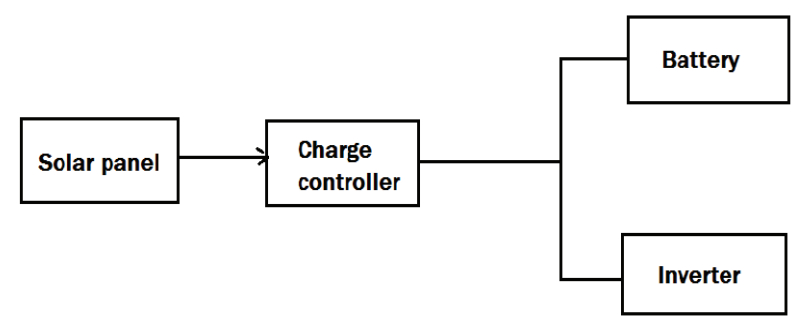

Fig. 2 Typical solar charge controller

There are different types of charge controllers and these include; shunt charge controller, series charge controller and the DC-DC converter charge controller.

The shunt controller is connected in parallel with the solar panel to regulate the charging of the battery from the solar panel. This is achieved by shorting the internal solar power [6]. The blocking diode of the shunt controller is connected in series with the battery to prevent the battery from discharging. This prevents the current from flowing back into the solar panel at night.

The series charge controller is connected in series with the solar panel output. There is a switch in between the panel and the controller to make or break the supply should the battery be fully charged. This is one of the most commonly used charge controllers due to its simplicity and protection from the battery load.

The DC-DC converters may be employed to operate as charge controllers depending on the type of circuit topology. One of the DC-DC converters that can be used as a charge controller is the inverted buck-boost converter. However, one of the disadvantages of using the inverted buck-boost converter is that its output voltage is negative. A positive output voltage is required to charge batteries and power a load.

There are different types of DC-DC controllers such as the Cuk converter and the (SEPIC) single ended primary inductor converter which both output positive voltages [7],
[8]. Cuk converters have the advantage of providing a continuous current for both the input and output. These

topologies are efficient in stepping up a large voltage. However, they have the problem of generating large output voltage ripples and are made up of large components. The non-inverting buck-boost converter has the advantage over the Cuk and (SEPIC) converters in that it uses smaller components that are efficient and cost effective.

In this paper the non-inverting buck-boost converter [9-15] is employed to improve the efficiency of the solar panel to charge the battery but still maintain a regulated output voltage to the battery.

Below are some of the equations used to design and simulate the converter. These equations are used to calculate the component values for the buck-boost converter before being loaded into the SIMetrix software for simulation purposes. The specifications used in the simulation software are minimum input voltage $V_{\text {in } \min }$ which is $18 \mathrm{~V}$, maximum input voltage $V_{\text {in } \max }$ which is $52 \mathrm{~V}$ depending on solar radiation as described in [16] with regards to commonly used renewable energy sources. The switching frequency $F_{S w}$ is $150 \mathrm{kHz}$ and the output voltage from the converter $V_{\text {out }}$ is $48 \mathrm{~V}$.

When the converter is operated in buck mode (step-down converter), equations (1) to (9) apply,

Equation (1) is used to calculate the duty cycle of the switch,

$$
D=\frac{V_{\text {out }}}{V_{\text {in } \max }}
$$

which is $92.3 \%, V_{\text {out }}$ and $V_{\text {in max }}$ have previously been defined, $D$ is the duty cycle.

Equation (2) is used to calculate output current,

$$
I_{\text {out }}=\frac{V_{\text {out }}}{R_{o}}
$$

Where $R_{o}$ is the output resistance for the circuit, $200 \mathrm{~m} \Omega$ and the output current is calculated to be $240 \mathrm{~A}$.

Equation (3) is used calculate the change in the output current and is given by,

$$
\Delta I_{\text {out }}=0.3 \times I_{\text {out }}
$$

The change in output current $\Delta I_{\text {out }}$ is calculated to be 72 A.

Equation (4) is used to calculate the period of the switching frequency,

$$
\Delta T=\frac{D}{F_{S W}}
$$

The period of the switching frequency $\Delta T$ is calculated to be $6.153 \mu \mathrm{s}$.

Equation (5) is used to calculate the change in output voltage $\Delta V$.

$$
\Delta V_{\text {out }}=1 \% \times V_{\text {out }}
$$


This results in $0.48 \mathrm{~V}$.

Equation (6) is used to calculate the value of the output capacitance used,

$$
C_{o}=\frac{\Delta T \times \Delta I_{\text {out }}}{\Delta V_{\text {out }}-\Delta I_{\text {out }} \times R_{E S R}}
$$

Where, $C_{o}$ is the output capacitance and $R_{E S R}$ is the effective resistance of $0.3 \Omega$. The output capacitance $C_{o}$ is calculated to be $20.9 \mu \mathrm{F}$.

Equation (7) is used to calculate the value of the inductor when the switch is closed,

$$
L=\frac{\left(V_{\text {in } \max }-V_{\text {out }}\right) \times\left(D \div F_{S w}\right)}{\Delta I_{\text {out }}}
$$

The inductance value is calculated to be $L=34.18 \mu \mathrm{H}$.

Equation (8) is used in calculating the input capacitance

$$
\begin{gathered}
\Delta \mathrm{V}_{\text {in }}=1 \% \times \mathrm{V}_{\text {in max }} \\
\Delta V_{\text {in }}=1 \% \times 52=0,52 \mathrm{~V} \\
\Delta I_{\text {in }}=\frac{\Delta I_{\text {out }}}{2}=36 \mathrm{~A} \\
C_{\text {in }}=\frac{\Delta T}{\left(\Delta V_{\text {in }} \div \Delta I_{\text {in }}\right)-R_{E S R}}
\end{gathered}
$$

Where $\Delta V_{\text {in }}$ is the change in input voltage and $\Delta I_{\text {in }}$ is the change in input current and all other variables are previously defined.

The calculated value of the input capacitance in buck mode is $C_{i n}=21.55 \mu F$.

Equation (9) is used to calculate the diode current $I_{D}$,

$$
I_{D}=(1-D) \times \Delta I_{\text {out }}
$$

The diode current is $I_{D}=5.544 \mathrm{~A}$

When the converter is operated in boost mode (step-up converter), equations (10) to (12) apply,

Equation (10) is used to calculate the duty cycle of the switch in this mode.

$$
D_{\text {max }}=1-\frac{V_{\text {in } \max }}{V_{\text {out }}}
$$

The duty cycle $D_{\max }=62.5 \%$

Equation (11) is used to calculate the value of the inductor in this mode when the switch is closed,

$$
L=\frac{V_{\text {in min }}\left(V_{\text {out }}-V_{\text {in min }}\right)}{\Delta I_{\text {out }} \times F_{\text {sw }} \times V_{\text {out }}}
$$

The inductance is calculated to be $L=1.042 \mu \mathrm{H}$

Equation (12) is used to calculate the output capacitance in the boost mode.

$$
C_{o}=\frac{D \times \Delta I_{\text {out }}}{F_{S w} \times \Delta V_{\text {out }}}
$$

Where $D$ is the duty cycle in boost mode all other variables are predefined.

As a result, the calculated value for the output capacitance in this mode is $625 \mu \mathrm{F}$.

All the calculated values for the buck and boost converter are entered into the SIMetrix circuit software in order to carry out the simulations as can be seen in Fig. 3 below.

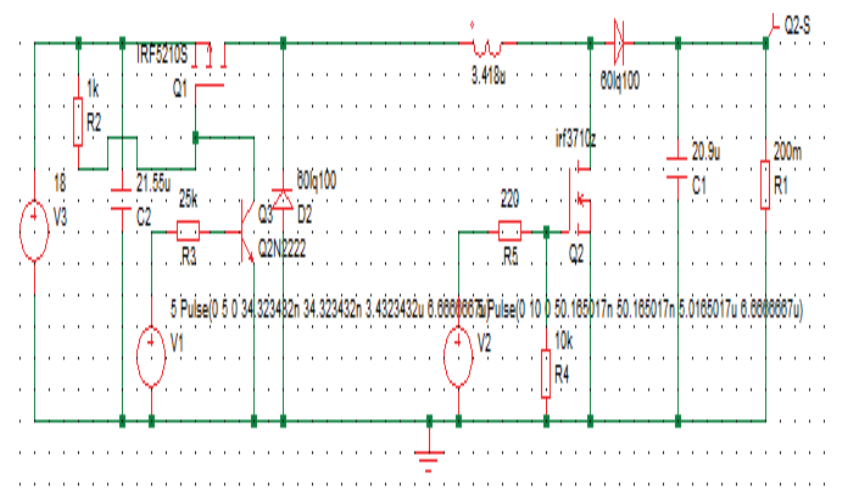

Fig. 3 Non-inverting buck-boost converter

III. RESULTS

\section{A. Simulation results for the buck-boost Converter in SIMetrix}

When the converter is used in boost mode with a voltage input of $18 \mathrm{~V}$ at a duty cycle of $62.5 \%$, the output voltage achieved is $48 \mathrm{~V}$ reaching a peak of $49.39 \mathrm{~V}$ with an output resistance of $2 \Omega$. We observe that the input voltage is stepped up from $18 \mathrm{~V}$ to a peak voltage of 49.39 $\mathrm{V}$. The prototype circuit was able to boost the input voltage as expected with a switching frequency $F_{S w}$ of $151.5 \mathrm{kHz}$. These results mean that the non-inverting buck-boost converter can regulate both the voltage and current. When the circuit is operating in the boost mode the input voltage is boosted from $18 \mathrm{~V}$ to $49.39 \mathrm{~V}$ as shown Fig. 4. This brings the output voltage close to the required output of 48 $\mathrm{V}$ to charge a battery bank. 


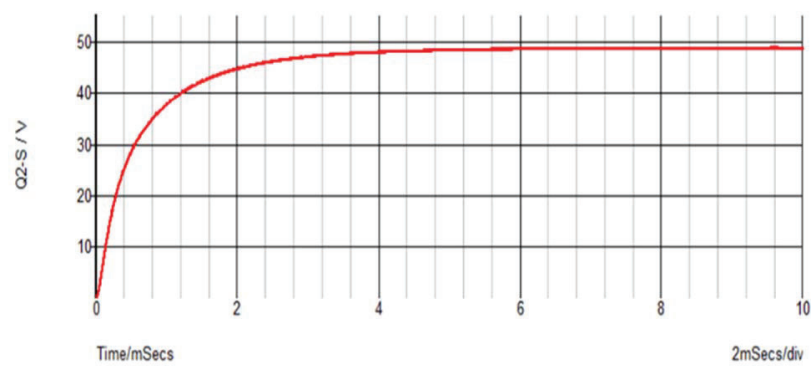

Fig. 4 Output voltage in boost mode with 2 ' $\Omega$ Resistance

When the converter is operated in boost mode with a voltage input of $18 \mathrm{~V}$ at a duty cycle of $62.5 \%$, output resistance set at $0.2 \Omega$, the output voltage achieved is 17.89 V. Fig.5 shows that the input voltage is actually stepped down from $18 \mathrm{~V}$ to $17.89 \mathrm{~V}$ in this case. The reason for this behavior is because the output resistance is reduced to 0.2 $\Omega$. This indicates that in boost mode the output resistance setting is very important and should be kept as high as possible.

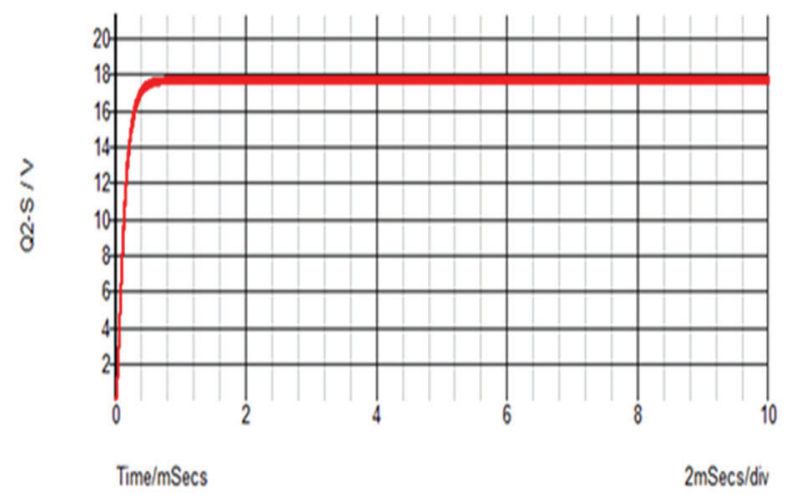

Fig. 5 Output voltage in boost mode with $0.2 \Omega$ Resistance

When the converter is operated in buck mode with an input voltage of $52 \mathrm{~V}$ at a duty cycle of $92.3 \%$ and an output resistance of $2 \Omega$, the settled output voltage achieved is $48.2 \mathrm{~V}$ with a peak voltage of $58.83 \mathrm{~V}$ as can be seen in Fig.6. In the buck mode the input voltage is stepped down from $52 \mathrm{~V}$ to a settled value of $48.2 \mathrm{~V}$. The high input voltage from the solar panels is stepped down to maintain the system voltage of $48 \mathrm{~V}$ that is used to charge the battery bank or power a load through an inverter. These results show that the non-inverting buck-boost converter can be used to regulate both the voltage and current supplied to the batteries. In buck mode the input voltage is chopped as shown in Fig. 6 to the required $48 \mathrm{~V}$.

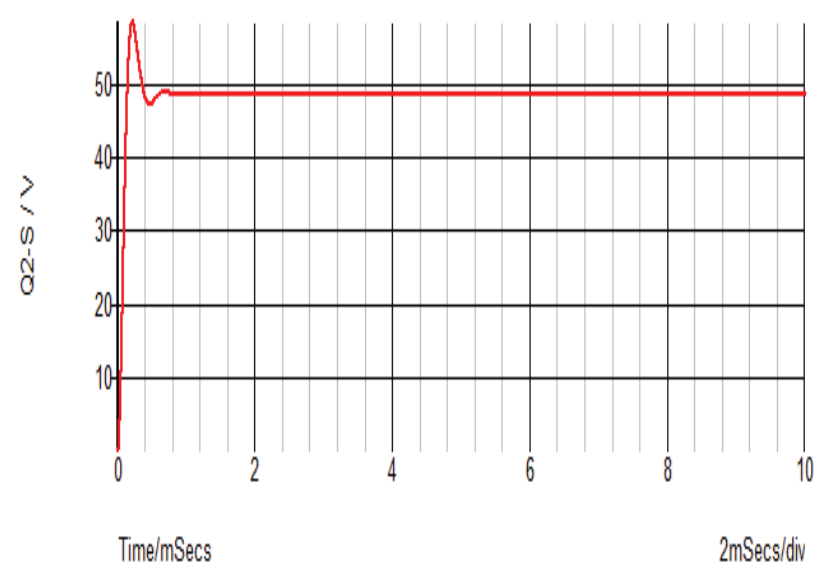

Fig. 6 Output voltage in buck mode with an input voltage of $52 \mathrm{~V}$ and an output resistance of $2 \Omega$

When the converter is operated in buck mode with an input voltage of $52 \mathrm{~V}$ at a duty cycle of $92.3 \%$ and an output resistance of $2.2 \Omega$, the settled output voltage achieved is $51.2 \mathrm{~V}$ with a peak voltage of $63.9 \mathrm{~V}$ as can be seen in Fig.7. In the buck mode it can be observed that the input voltage was stepped down from $52 \mathrm{~V}$ to a settled value of $51.2 \mathrm{~V}$ with a peak of $63.9 \mathrm{~V}$. In this case the buck mode struggled slightly to bring the voltage down to $48 \mathrm{~V}$ and settled on $51.2 \mathrm{~V}$ due to the slight increase in the output resistance to $2.2 \Omega$. However, the results show that the noninverting converter in buck mode is still able to regulate the voltage and current and bring the input voltage of $52 \mathrm{~V}$ down closer to the required output of $48 \mathrm{~V}$.

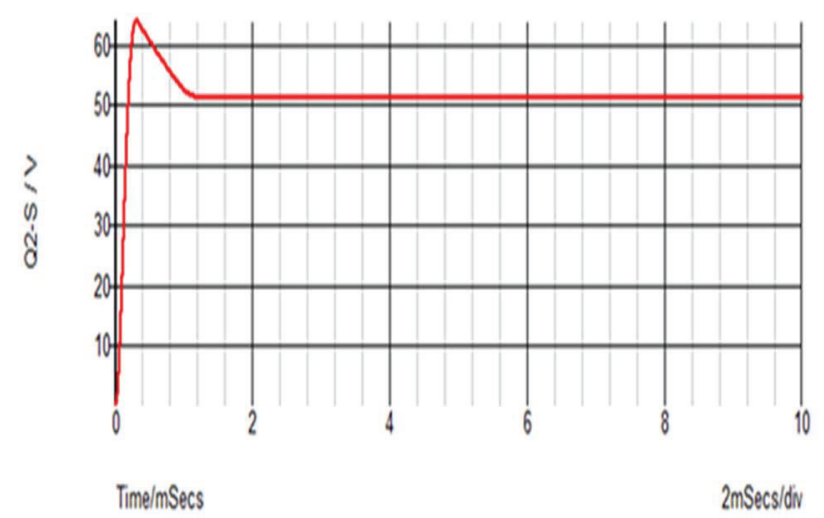

Fig. 7 Output voltage in buck mode mode with an input voltage of $52 \mathrm{~V}$ and an output resistance of 2.2 .

B. Operation of the complete PV based power supply

The non-inverting buck-boost converter (Solar Charge controller) is used to either step down (buck) or step up (boost) the output voltage to the batteries. The system specifications range from $18-30 \mathrm{~V}$ for the input voltage and centre around $48 \mathrm{~V}$ for the output voltage to charge the batteries. When the solar panel extract more or less solar energy from the sun, then the non-inverting buck-boost 
converter will regulate the output voltage to $48 \mathrm{~V}$. The $\mathrm{ON}$ and OFF switching or connection of the buck-boost converter between the solar panels and the battery pack is performed by the PIC16F877 microcontroller. The complete prototype is shown in Fig. 8 below.

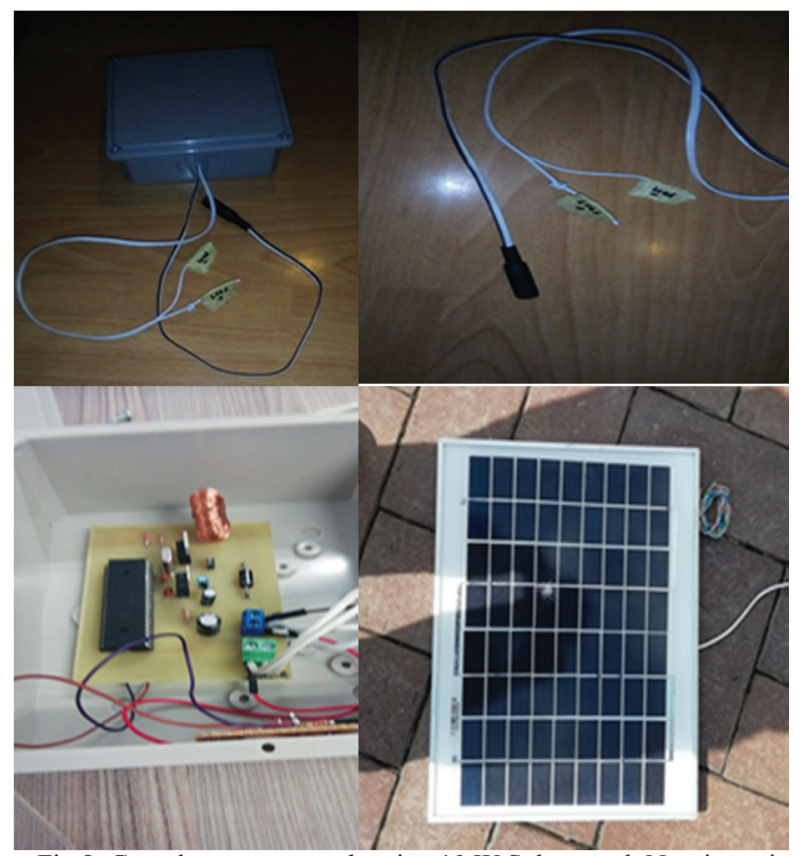

Fig 8. Complete prototype showing $10 \mathrm{~W}$ Solar panel, Non-inverting buck-boost converter, Output leads to a load and PIC microcontroller.

\section{CONCLUSION}

A non-inverting buck-boost converter was simulated in SIMetrix software, and then subsequently built and tested. The non-inverting buck -boost converter can be used as a solar charge controller to regulate both the voltage and current used to charge batteries in a PV system. Graphs have been used to show that the buck-boost converter is used to regulate the output voltage to $48 \mathrm{~V}$ for charging batteries in the PV system. The ON and OFF switching and connection of the solar charge controller between the solar panels and the batteries is carried out by using the PIC16F877 microcontroller in the complete PV based power supply.

\section{ACKNOWLEDGEMENT}

[13] C. Chen, C. Wei, K. Wu, "Integrated non-inverting buck-boost DCDC converter with average -current-mode control", International Conference on Circuits and Systems (ICCAS), IEEE 2012.

[14] N. Namjoo, A. Hajizadeh, "Adaptive control of non-inverting buckboost converter", The $5^{\text {th }}$ Power Electronics, Drive Systems and Technologies Conference (PEDSTC 2014), 5- $6^{\text {th }}$ Feb 2014, Tehran, Iran.

[15] Z. Yu, H. Kapels, K. Hoffmann, "Extreme High Efficiency NonInverting Buck-Boost Converter for Energy Storage Systems", International Exhibition and Conference for Power Electronics, Intelligent motion, Renewable Energy and Energy Management, PCIM Europe 2016.
We would like to thank the University of Johannesburg and the University of South Africa for the use of their resources to complete this work.

\section{REFERENCES}

[1] International Energy Agency (2017). Available from: https://www.iea.org/energyaccess/database/

[2] Gogula, R.R (2015). A sustainable hybrid off grid power generation systems suitable for a remote coastal area in Oman. 8th IEEE GCC Conference and Exhibition, 1-4. Available from: https://0ieeexplore-ieeeorg.ujlink.uj.ac.za/stamp/stamp.jsp?tp=\&arnumber=7060054

[3] Misak, S. and Prokop, L (2010). Off-grid power system. 9th International conference on environment and electrical engineering, 1-5. Available from: https://0-ieeexplore-ieeeorg.ujlink.uj.ac.za/stamp/stamp.jsp?tp=\&arnumber=5490003

[4] Jayasankar, V.N., Gururaj, M.V. and Vinatha, U. (2016). A study on hybrid renewable energy source interface to the non-ideal grid at distribution level with power quality improvements, 6th International conference on power systems (ICPS), 1-5. Available from: https://0-ieeexplore-ieeeorg.ujlink.uj.ac.za/stamp/stamp.jsp?tp=\&arnumber=7584239

[5] Articsun, renewable101. Available from: http://www.arcticsun1lc.com/resources/renewable-101/wind-energy/

[6] Harington, S. and Dunlop, J. (1992). Battery charge controller characteristics in photovoltaic systems. IEEE aerospace and electronic systems magazine, 1-7. Available from: https://0ieeexplore-ieee-

org.ujlink.uj.ac.za/stamp/stamp.jsp?tp=\&arnumber=151141

[7] Riawan, D.C. and Nayar, C.V. (2007). Analysis and design of a solar charge controller using cuk converter. Australasian universities power engineering conference, 1-6. Available from: https://0ieeexplore-ieee-

org.ujlink.uj.ac.za/stamp/stamp.jsp?tp $=$ \&arnumber $=4548115$

[8] Suryoatmojo, H. et al (2018). Design and analysis of high gain modified SEPIC converter. IEEE international conference on innovative research and development, 1-6. Available from: https://0-ieeexplore-ieee-

org.ujlink.uj.ac.za/stamp/stamp.jsp?tp=\&arnumber=8376319

[9] Ching-Wei, C and Chia-Ling, W. (2011). Single-inductor fourswitch non-inverting buck-boost dc-dc converter. International Symposium on VLSI Design, Automation and Test, 1-4. Available from: https://0-ieeexplore-ieeeorg.ujlink.uj.ac.za/stamp/stamp.jsp?tp=\&arnumber=5783629

[10] V. Siddhartha, Y. Hote, "Non-Inverting Buck-boost Derived Hybrid Converter", International Conference on Emerging Trends in Electrical Electronics and Sustainable Energy Systems, India, March 2016.

[11] E. Schaltz, P. Rasmussen, A. Khaligh, "Non-inverting buck-boost converter for fuel cell applications", $34^{\text {th }}$ Annual Conference of IEEE Industrial Electronics, 2008.

[12] O. Almasi, V. Fereshtehpoor, M. Khooban, F. Blaabjerg, "Analysis, control and design of a non-inverting buck-boost converter: A bump-less two - level T-S fuzzy PI control", ISA Transactions, Vol.67, pp 515-527, March 2017.

[16] A. Tomaszuk and A. Krupa, "High efficiency high step-up DC/DC converters - a review", Bulletin of the Polish Academy of Sciences, Technical Sciences, Vol. 59, No. 4, 2011. 